\title{
Glial Cells Are Increased Proportionally in Transgenic Optic Nerves with Increased Numbers of Axons
}

\author{
Julia F. Burne, ${ }^{1}$ Julie K. Staple, ${ }^{2}$ and Martin C. Raff ${ }^{1}$ \\ ${ }^{1}$ Medical Research Council Developmental Neurobiology Programme, MRC Laboratory for Molecular Cell Biology and the \\ Biology Department, University College London, London, WC1E 6BT, United Kingdom, and ${ }^{2}$ Glaxo Institute for Molecular \\ Biology, 1228 Plan-les-Ouates, Geneva, Switzerland
}

To study how an increase in axon number influences the number of glial cells in the mammalian optic nerve, we have analyzed a previously described transgenic mouse that expresses the human bcl-2 gene from a neuron-specific enolase promoter. In these mice, the normal postnatal loss of retinal ganglion cell axons is greatly decreased and, as a consequence, the number of axons in the optic nerve is increased by $\sim 80 \%$ compared with wild-type mice. Remarkably, the numbers of oligodendrocytes, astrocytes, and microglial cells are all increased proportionally in the transgenic optic nerve. The increase in oligodendrocytes apparently results from both a decrease in normal oligodendrocyte death and an increase in oligodendrocyte precursor cell proliferation, whereas the increase in astrocytes apparently results from an increase in the proliferation of astrocyte lineage cells. Unexpectedly, the transgene is expressed in oligodendrocytes and astrocytes, but this does not seem to be responsible for the increased numbers of these cells. These findings indicate that developing neurons and glia cells can interact to adjust glial cell numbers appropriately when neuronal numbers are increased. We also show that the expression of the $\mathrm{bcl}-2$ transgene in retinal ganglion cells protects the cell body from programmed cell death when the axon is cut, but it does not protect the isolated axon from Wallerian degeneration, even though the transgene-encoded protein is present in the axon.

Key words: oligodendrocytes; astrocytes; oligodendrocyte death; optic nerve; astrocyte proliferation; Wallerian degeneration
The size of an organism or organ depends primarily on how many cells it contains. It is not known, however, how cell numbers are controlled or how the proportions of different cell types are determined and maintained. We have studied these problems in the rodent optic nerve, one of the simplest parts of the CNS.

The mammalian optic nerve contains three main types of glial cells: astrocytes, oligodendrocytes, and microglial cells. Astrocytes develop from neuroepithelial cells in the optic stalk, the primordium of the optic nerve. Oligodendrocytes develop from precursor cells that migrate into the nerve (Small et al., 1987), and microglial cells are derived from the hemopoietic system. The nerve also contains the axons of retinal ganglion cells (RGCs), but no intrinsic neurons.

We have been particularly interested in how the number of oligodendrocytes in the rat optic nerve is determined. Because oligodendrocytes are normally postmitotic (Gard and Pfeiffer, 1989; Hardy and Reynolds, 1991) and their precursor cells proliferate extensively (Temple and Raff, 1986), their final number depends on how many precursors migrate into the nerve and how many times each divide before differentiating. Programmed cell death (PCD) also plays a major role in controlling oligodendrocyte numbers: at least half of the oli-

\footnotetext{
Received Sept. 20, 1995; revised Dec. 18, 1995; accepted Dec. 19, 1995.

This work was supported by the Medical Research Council, United Kingdom. We thank Jean-Claude Martinou for generously providing transgenic mice, David Mason and David Colman for supplying antibodies, John Parnavelas for help with EM cell identification, Jim Voyvodic for the use of his computer program, and Sara Ahlgren and Barbara Barres for helpful comments on this manuscript.

Correspondence should be addressed to Julia Burne, MRC Laboratory for Molecular Cell Biology, University College London, Gower Street, London WCIE 6BT, UK.

Copyright 1996 Society for Neuroscience $0270-6474 / 96 / 162064-10 \$ 05.00 / 0$
}

godendrocytes in the nerve undergo PCD soon after they develop (Barres et al., 1992). Optic nerve axons influence oligodendrocyte numbers in several ways: they promote precursor cell proliferation (Barres and Raff, 1993) and they promote oligodendrocyte survival (Barres et al., 1993). Barrcs et al. (1993) proposed that normal oligodendrocyte death might help match the number of oligodendrocytes to the number of axons requiring myelination, just as normal neuronal death is thought to help match the number of neurons to the number of target cells the neurons innervate (Cowan et al., 1984; Oppenheim, 1991): they suggested that newly formed oligodendrocytes require a signal(s) from axons to avoid PCD, and only about half manage to receive enough signal to survive.

Here we have studied transgenic mice that express the human $b c l-2$ gene controlled by a neuron-specific enolase (NSE) promoter. Because $b c l-2$ suppresses PCD (Reed, 1994), these mice have increased numbers of various types of neurons, including RGCs (Dubois-Dauphin et al., 1994; Martinou et al., 1994). We show that these mice have almost twice the normal number of axons in the adult optic nerve, attributable to a decrease in the normal postnatal loss of axons. In addition, the nerves contain approximately twice the number of oligodendrocytes, astrocytes, and microglial cells. The increased number of oligodendrocytes apparently results from both a decrease in oligodendrocyte death and an increase in oligodendrocyte precursor proliferation, whereas the increase in astrocyte numbers apparently results from increased proliferation of astrocytes. We also show that the $b c l-2$ transgene is expressed in oligodendrocytes and astrocytes, but this is unlikely to be responsible for the increase in glial cell numbers. Finally, we demonstrate that the expression of the $b c l-2$ transgene in $\mathrm{RGCs}$ 
protects the soma but not the isolated axon from axotomyinduced degeneration.

\section{MATERIALS AND METHODS}

Chemicals. All chemicals were from Sigma (St. Louis, MO), unless otherwise stated.

Animals. Transgenic mice expressing human $b c l-2$ under the control of the NSE promoter were provided by Dr. J-C. Martinou (Martinou et al., 1994). The two mouse lines (numbers 71 and 73) that we have used in this study were descendants of two founders. Transgenic male mice were mated with normal $\mathrm{C} 57 \mathrm{BL} / 6 \mathrm{~J}$ females. The day of birth was designated as P0. Offspring were screened for the transgene by immunofluorescence staining with a mouse monoclonal anti-human Bcl-2 antibody (Pezzella et al., 1990) using either frozen sections of retinae or freshly dissociated retinal cells, as described below.

Electron microscopy, axon and cell counting. Mice were perfused with $4 \%$ paraformaldehyde and $2 \%$ glutaraldehyde in $0.1 \mathrm{M}$ phosphate buffer, $\mathrm{pH}$ 7.4. The optic nerves were removed, immersed in the same fixative overnight at $4^{\circ} \mathrm{C}$, and post-fixed in $1 \%$ osmium tetroxide in the same buffer for $1 \mathrm{hr}$. After washing three times, the nerves were dehydrated in a graded series of alcohols and embedded in epoxy resin (Sigma). Thin transverse sections were cut with an LKB ultramicrotome (Leica, Milton Keynes, U.K) and mounted on Formvar-coated single-slot grids (Sigma), counter-stained with uranyl acetate and lead citrate, and examined in a JOEL 100 CX II electron microscope (Tokyo, Japan) at $80 \mathrm{kV}$. Optic nerves from three transgenic mice and three wild-type littermates were studied at each age. Both of the nerves from each animal were studicd in the case of adults.

A low-power micrograph (magnification 300 or $380 \times$ ) was taken of each entire transverse section of the nerve. This was used to measure the area of the nerve using a "Summa Sketch" graphics digitizing drawing tablet (Summagraphics, Seymour, CT) and the CIGAL computer program [formerly called IMAGR (Purves and Voyvodic, 1987)] with suitable calibration. A second series of micrographs was taken at higher magnification ( $6350 \times$ for P0, P10, P15 nerves; $2900 \times$ for adult nerves). The first micrograph of each series was taken at the pial surface, and serial ones were taken across the nerve until the other pial surface was reached. The micrographs were put together to create a continuous picture, representing a ribbon of tissue from one side of the nerve to the other. We counted the total number of axons in this nontage and measured the area of the montage with the drawing tablet. We then calculated the fraction of the nerve area that the montage represented (which was between 5 and $10 \%$ ) and multiplied this fraction by the number of axons counted to estimate the number of axons in the whole nerve.

We measured the area and circumference of axons in adult nerves using the drawing tablet and a line drawn through the center of the micrographs to sample the axons; only axons crossed by this line werc measured. The number of axons measured in each sample was $\sim 400$. The results from three transgenic nerves and from three wild-type nerves were pooled for comparison.

To count the numbers of each type of glial cell, cells were located at a magnification of $2900 \times$, and then the magnification was increased to $10,000 \times$ to examine the cellular ultrastructure. The entire section was systematically scanned for every cell with a visible nucleus.

Measurement of DNA. The total amount of DNA in the optic nerve was measured as described previously (Barres et al., 1992). Pairs of nerves were dissected by initially cutting behind the eye and then removing the brain with the optic nerves still attached. Both optic nerves were then cut at the chiasm and placed in digestion buffer containing $10 \mathrm{~mm}$ Tris $\mathrm{HCl}$, $50 \mathrm{~mm}$ EDTA, $0.1 \%$ SDS, and $200 \mu \mathrm{g} / \mathrm{ml}$ proteinase $\mathrm{K}$. The nerves werc minced with scissors and incubated at $55^{\circ} \mathrm{C}$ for $48 \mathrm{hr}$. After digestion, the final volume was measured and the DNA was assayed with a fluorimetric method (Labarca and Paigen, 1980) that measures the amount of Hoechst 33258 dye that binds to DNA, using a Perkin-Elmer LS-5 luminescence spectrometer (Norwalk, CT). The amount of DNA was translated into cell number by assuming $5.8 \mathrm{pg}$ of DNA per diploid cell (Ausubel et al., 1991). DNA standard curves were prepared using the same percentage of SDS that was present in the tissue samples. No correction was made for the number of cells in $\mathrm{S}$ and $\mathrm{G} 2$ phases of the cell cycle, which contain $>2 \mathrm{~N}$ DNA.

Frozen sections. Mice were anesthetized with a lethal injection of Sagatal. They were then perfused through the heart with $0.1 \mathrm{M}$ phosphate buffer, $\mathrm{pH} 7.4$, to remove blood cells, followed by $4 \%$ paraformaldehyde in the same buffer. Retinac or optic nerves were removed and immersed in the same fixative overnight at $4^{\circ} \mathrm{C}$. They were then transferred to $1 \mathrm{M}$ sucrose in phosphate buffer until equilibrated, embedded in OCT compound (Miles, Elkhart, IN), and frozen in liquid nitrogen. Frozen sections were cut at $10 \mu \mathrm{m}$ and collected onto glass microscope slides that had been previously coated with $1 \%$ gelatin. Sections were either stained immediately or stored at $-20^{\circ} \mathrm{C}$ until use.

Staining for transgene expression in retina. Frozen sections ol retina were post-fixed in methanol at $-20^{\circ} \mathrm{C}$ for $10 \mathrm{~min}$, washed, and incubated overnight at $4^{\circ} \mathrm{C}$ with a monoclonal anti-human $\mathrm{Bcl}-2$ antibody (hybridoma supernatant, diluted $1: 1$ in 'Tris-buffered saline containing $1 \%$ bovine serum albumin (BSA) and $10 \mathrm{~mm}$ L-lysine; TBLS). The antibody was visualized with a fluorescein-coupled goat anti-mouse immunoglobulin (G anti-MIg-Fl; Jackson ImmunoResearch Laboratories, West Grove, PA) diluted 1:100 in TBLS. Where dissociated retinal cells were tested, retinac were dissociated without enzymes and the cells were allowed to adhere to poly-D-lysine (PDL; $0.01 \mathrm{mg} / \mathrm{ml}$ )-coated coverslips for $20 \mathrm{~min}$ at room temperature in Minimal Eagle's Medium (MEM: Gibco, Gaithersburg, MD), containing $25 \mathrm{~mm}$ IIEPES buffer and 1\% BSA. Cells were fixed with methanol and stained as described above, except that the incubations were for $30 \mathrm{~min}$ at room temperature. All slides and coverslips were washed in buffer, mounted in Citifluor (Citifluor UKC, UK) and examined in a Zciss Axioskop fluoreseence microscope (Thornwood, NY).

Staining of dead cells in optic nerve sections. To determine the number of dead cells in optic nerves, frozen sections were stained with propidium iodide (PI) (Barres et al.. 1992). First. sections were post-fixed with 7(1); ethanol at $-20^{\circ} \mathrm{C}$ for $10 \mathrm{~min}$. They were then incubated in $\mathrm{PI}$ and DNase-free RNase A $\left(100 \mathrm{ug} / \mathrm{ml}\right.$ ) for $15 \mathrm{~min}$ at $37^{\circ} \mathrm{C}$ (RodriguezTarduchy et al., 1990). The slides were subsequently washed in buffer, mounted in Citifluor, and examined as described.

The total number of dead cells in a nerve was determined by counting all the pyknotic cells in all of the sections prepared from the entire nerve. Condensed or fragmented nuclei, which were also phase-dark, were counted as pyknotic, and only cells within the boundary of the glial limiting membrane were considered. No correction for section thickness was made.

To determine whether any of the dead cells were astrocytes, we prepared sections of postnatal day 7 (P7) optic nerves, post-fixed them in methanol, and incubated them overnight in a rabbit antiserum against glial fibrillary acidic protein (GFA.P) (Pruss, 1979), diluted 1:100 in TBLS. The antibodies were visualized with sheep anti-rabbit fluorescein (Sh anti-RIg Fl; Jackson ImmunoResearch Laboratories) diluted 1:100. The sections were then stained with PI as described. To deternine whether astrocytes that undergo PCD maintain their GFAP, we cultured P8 optic nerves as explants on polycarbonate filters (Costar Nuclepore, Charlotte, NC), $0.8 \mu \mathrm{m}$ pore size, for 5 d floating in DMEM with glutamax (Gibco). We induced PCD with a high concentration $(1 \mu \mathrm{M})$ of the protein kinase inhibitor staurosporine, which induces PCD in all nucleated cell types we have studied (Raff et al., 1993). We then sectioned and stained the nerves with anti-GFAP antibodies.

Bromodeoxyuridine incorporation. To assess the number of proliferating cells in the developing optic nerve, bromodeoxyuridine (BrdU; $0.1 \mathrm{mg} /$ $\mathrm{gm}$ ) was injected into the peritoneum of mice of various ages 1 hr before they were killed. Frozen sections of optic nerves were prepared as described, except that sections were collected on 3-aminopropyltriethoxysilane-coated slides. The sections were treated with $50 \% \mathrm{HCl}$ (together with $1 \%$ Triton X-100) for 20 min at room temperature to denature the DNA. After washing in buffer, the BrdU incorporated into DNA was visualized with a fluorescein-conjugated mouse monoclonal anti-BrdU antibody (diluted 1:3 in TBLS, Beckton Dickinson, Mountain Vicw, CA). All of the sections from each nerve were stained, and the total numbers of $\mathrm{BrdU}^{+}$cells within the boundary of the glial-limiting membrane were counted.

To determine what proportion of the dividing cells in P5 nerves were astrocytes, we injected P5 mice with BrdU as above, except that two injections were given $2 \mathrm{hr}$ apart. Optic nerves were dissociated with papain (as described below) and cultured overnight on PDL-coated coverslips $(30,000$ cells per coverslip) in a modified Bottenstein-Salo (B-S) medium (Bottenstein and Sato, 1979) containing insulin $(10 \mu \mathrm{g} / \mathrm{ml})$ and $N$-acetyl-L-cysteine $(25 \mu \mathrm{M})$. The cells were fixed with cold methanol, stained for GFAP and BrdU as described above [except that the Bu20a anti-BrdU monoclonal antibody (Magaud et al., 1989) was used as hybridoma supernatant diluted 1:1 with TBLS (the antibody was visualized with $\mathrm{G}$ anti-MIg $\mathrm{Fl}$ )], and preincubated in $2 \mathrm{M} \mathrm{HCl}$ for $10 \mathrm{~min}$, followed by $0.1 \mathrm{M}$ sodium borate for $10 \mathrm{~min}$ to denature the DNA 
Staining for transgene expression in optic nerve glial cells and axons. Optic nerves were removed and dissociated with $30 \mathrm{U} / \mathrm{ml}$ papain (Worthington Biochemical, Freehold, NJ) in MEM/HEPES containing L-cysteine $(0.4$ $\mathrm{mg} / \mathrm{ml}$ ) and DNAase (0.04\%). The nerves were cut into small pieces and incubated in papain solution at $37^{\circ} \mathrm{C}$ for $75 \mathrm{~min}$ for $\mathrm{P} 7$ nerves and $90 \mathrm{~min}$ for P14 nerves. Cells were dissociated by passing the nerve fragments through a 21 - and then a 23-gauge necdle in medium containing ovomucoid $(2 \mathrm{mg} / \mathrm{ml})$ and DNAase $(0.04 \%)$. After washing, the cells were plated onto PDL-coated coverslips in $20 \mu \mathrm{l}$ of MEM/HEPES containing $1 \%$ BSA, allowed to adhere for $20 \mathrm{~min}$, and then fixed with methanol. The cells were stained with a rabbit antiserum against myelin basic protein (MBP; a gift from D. Colman, diluted $1: 100$ in TBLS) to identify oligodendrocytes, or with a rabbit antiserum against GFAP to identify astrocytes. The antibodies were visualized with Sh anti-RIg conjugated to Texas Red (Jackson Laboratories, diluted 1:100). The cells were then stained with the monoclonal antibody against human $\mathrm{Bcl}-2$ as described above. The $\mathrm{G}$ anti-MIg Fl used to visualize the anti-Bcl-2 antibody did not recognize the rabbit antibodies.

To determine whether the $b c l-2$ transgene was expressed in microglial cells, P7 optic nerve cells were cultured for $3 \mathrm{~d}$ in DMEM containing $10 \%$ fetal calf serum (FCS). The cells were then labeled with normal rabbit serum (diluted 1:100), followed by Sh anti-RIg Texas Red to localize Fc receptors on microglial cells (Raff et al., 1979). The cells were then fixed with methanol and stained with anti-human Bcl-2 antibody as described.

To compare the brightness of the immunofluorescence staining in $\mathrm{Bcl}-2^{+}$cells from transgenic lines 71 and 73 , stained cells were viewed on a Bio-Rad MRC 1000 confocal laser scanning fluorescence microscope (Richmond, CA). Individual $\mathrm{Bcl}-2^{+}$cells were selected at random, and the "area" command was used to collect brightness readings. Twenty frames were collected for each image, and the average fluorescence intensities were converted into numerical readings of arbitrary values.

To study the expression of the transgene in the optic nerve, frozen sections of adult optic nerves were stained with anti-human Bcl-2 antibody as described above for cell staining.

Survival of dissociated optic nerve glial cells in culture. To determine whether the expression of human Bcl-2 in oligodendrocytes could protect them when they are deprived of survival signals in culture, we dissociated P8 optic nerve cells using $0.125 \%$ trypsin for $30 \mathrm{~min}$ in Earle's balanced salt solution (EBSS; Gibco). After dissociation, the cells were washed in $30 \%$ FCS and cultured at low density $(10,000$ cells per coverslip) in DMEM. Both wild-type and transgenic cells were mixed together in these cultures so that they were exposed to the same environment. After 1 and $3 \mathrm{~d}$ in culturc, eclls were stained with a monoclonal anti-galactocerebroside (GC) antibody (ascites fluid diluted 1:100 in TBLS) (Ranscht et al., 1982), followed by Texas-Red-coupled goat anti-mouse immunoglobulin ( $\mathrm{G}$ antiMIg Tex Red; Jackson Laboratories) diluted 1:100 in TBLS to identify the oligodendrocytes. The cells were then fixed with methanol and stained with anti-human $\mathrm{Bcl}-2$ as above, except that the antibody was visualized with a class-specific, fluorescein-coupled goat anti-mouse IgG1 (G ant-MIgG1 Fl; Nordic, Captistrano Beach, CA) diluted 1:50 in TBLS. We then counted the proportion of $\mathrm{GC}^{+}$oligodendrocytes that were $\mathrm{Bcl}-2^{+}$.

Optic nerve transection. P18 mice were anesthetized using Hypnorm and Diazepam. The left eye was retracted to allow access to the optic nerve, which was cut with ophthalmology scissors just behind the globe. Successful transection was confirmed by visual inspection when the mouse was killed 4 d later. Frozen sections of the nerves were prepared and slained with PI as described above. Sonte sections were also stained with the RT97 monoclonal anti-neurofilament (diluted 1:500) (Wood and Anderton, 1981) overnight at $4^{\circ} \mathrm{C}$, followed by $\mathrm{G}$ anti-MIg Fl.

Retinal explant cultures. Neural retinae were removed from adult mice in PBS. The whole retina was placed (pigment layer down) on a polycarbonate filter floating in $10 \mathrm{ml}$ of DMEM in a petri dish at $37^{\circ} \mathrm{C}$ in $5 \%$ $\mathrm{CO}_{2}$. After $4 \mathrm{~d}$, the tissue was fixed in $4 \%$ paraformaldehyde in $0.1 \mathrm{M}$ phosphate, cryoprotected with $1 \mathrm{~m}$ sucrose, and $10 \mu \mathrm{m}$ frozen sections were cut through the nerve head to the periphery of the retina; every third section was saved. The sections were post-fixed with methanol and stained with antiserum against protein gene product 9.5, which is restrictcd to horizontal cells and RGCs in the mammalian retina (Bonfanti et al., 1992). The antiserum was diluted 1:1000 in TBLS, applied overnight at $4^{\circ} \mathrm{C}$, and visualized with Sh anti-RIg Texas Red. To count the number of $\mathrm{RGC}$ cell somata that remained after $4 \mathrm{~d}$ in culture, $\mathrm{PGP}^{\prime}$ cells in the ganglion cell layer were counted in $40 \times 0.25 \mathrm{~mm}$ lengths (measured with a graticule), sampled at random from the nerve head to the periphery of the retina.

To determine whether the human $\mathrm{Bcl}-2$ protein is expressed in the
Table 1. Axons in adult optic nerves

\begin{tabular}{|c|c|c|}
\hline & Wild type & Transgenic \\
\hline Axon number & $54,666 \pm 2,471$ & $97,400 \pm 7,124$ \\
\hline $\begin{array}{l}\text { Nerve area } \\
\quad \text { (cross section) }\end{array}$ & $103 \pm 2 \times 10^{3} \mu \mathrm{m}^{2}$ & $200 \pm 20 \times 10^{3} \mu \mathrm{m}^{2}$ \\
\hline $\begin{array}{l}\text { Axon area } \\
\text { (cross section) }\end{array}$ & $0.34 \pm 0.008 \mu \mathrm{m}^{2}$ & $0.35 \pm 0.007 \mu \mathrm{m}^{2}$ \\
\hline $\begin{array}{l}\text { Myelinated } \\
\text { axons }(\%)\end{array}$ & $96.3 \pm 0.96$ & $96.1 \pm 0.88$ \\
\hline
\end{tabular}

Counts and measurements were made on electron micrographs of transverse sections of optic nerves from 3-month-old wild-type and transgenic mice (line 73), as described in Materials and Methods. The nerve area and axon counts were made on one section from each of a pair of optic nerves taken from threc animals, giving a total of six sections per group. Approximately 1,400 individual axon areas were measured per group. Approximately 1,200 axons taken from three different animals per group were assessed for myelination; an axon was counted as myelinated if it had at least one complete wrap of myelin. The results are presented as the mean \pm SEM

axons of transgenic RGCs as well as in their cell bodies, small fragments of $P()$ retina were cultured on glass coverslips coated with $P D L$ and laminin $(5 \mu \mathrm{g} / \mathrm{ml})$. Explants were grown in $\mathrm{B}-\mathrm{S}$ medium containing $1 \%$ FCS and insulin $(10 \mu \mathrm{g} / \mathrm{ml})$ at $37^{\circ} \mathrm{C}$ in $5 \%$ CO, After $3 \mathrm{~d}$, when axons had grown out from the explants, the cultures were stained with anti-human Bcl-2 antibody as described.

\section{RESULTS}

The hetcrozygous transgenic mouse line 73 expresses a human $b c l-2$ gene in many CNS neurons, including $\mathrm{KGCs}$, and, as a result, the number of neurons and the sizes of the brain and optic nerves are increased compared with normal, although in othcr respects the mice appear normal. We crossed these mice with C57BL/6J mice and stained retinal cells from each member of the litters used with an anti-human $\mathrm{Bcl}-2$ antibody to identify the transgenic and nontransgenic (wild-type) progeny. As expected, we found that $\sim 50 \%$ of the progeny expressed the $b c l-2$ transgene. No cells were stained in $\mathrm{C} 57 \mathrm{BL} / 6 \mathrm{~J}$ retinae.

\section{Optic nerve axons}

To examine the axons in the optic nerve, we prepared photomontages of cross sections from both optic nerves from three adult transgenic mice and three adult wild-type siblings, as described in Materials and Methods. As shown in Table 1, the average surface area of the optic nerves in transgenic mice was approximately twice that of nerves in wild-type littermates, and the number of axons was $\sim 80 \%$ greater. The number of axons in wild-type mice is in good agreement with those reported by Williams et al. (1990) for the same strain of mice. The average diameter and area of individual axons, as well as the proportion of the axons that were myelinated, were about the same in transgenic and wild-type optic nerves. The average length of the optic nerves measured in 6-month-old animals also was not significantly different in the two types of mice $(4.7 \pm 0.3 \mathrm{~mm}$ in transgenic mice vs $4.9 \pm 0.2 \mathrm{~mm}$ in wild-type mice, mean $\pm \mathrm{SEM} ; n=10$ and 6 , respectively).

As shown in Figure 1, the average number of axons present at birth was a little greater in transgenic optic nerves than in wildtype nerves, but this difference was not statistically significant. As expected, in both cases the numbers of axons decreased postnatally, presumably reflecting the normal death of RGCs, but the decrease was much greater in wild-type nerves than in transgenic nerves.

\section{Optic nerve glial cells}

To compare the total numbers of glial cells in the optic nerves of transgenic and wild-type mice, we measured the total amount of 


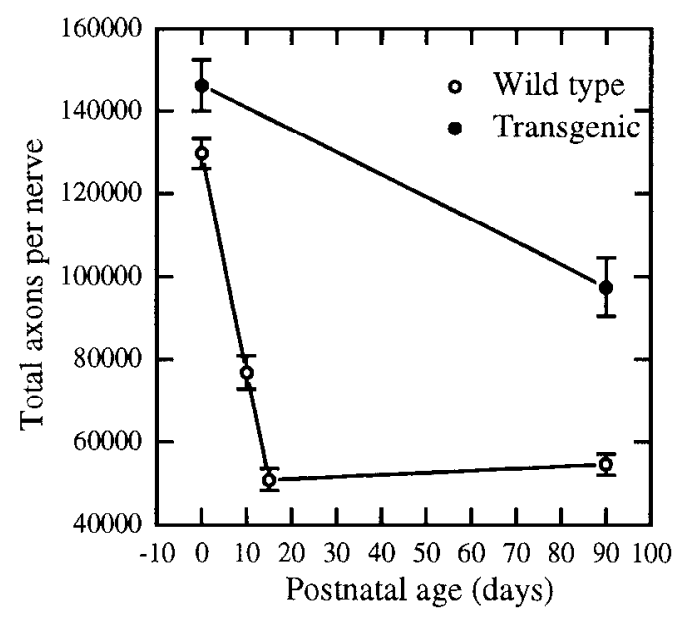

Figure 1. Axon numbers in optic nerves of wild-type and transgenic (line 73) mice from various ages. The results are expressed as mean \pm SEM of counts from one nerve from three animals at each age, except for adults, in which both nerves were counted from three animals. The differences between the transgenic and wild-type nerves at $\mathrm{P}()$ are not statistically different when analyzed by Student's $t$ test $(p>0.05)$.

DNA in the nerves and divided the values by the amount of DNA per mouse diploid cell. As shown in Figure 2, there was no significant difference in the total number of cells at embryonic day 17.5 (E17.5) between transgenic and wild-type littermates. There was a small but significant difference at birth, and this difference steadily increased until about P30, when there were almost twice as many cells in transgenic nerves than in wild-type nerves; this difference persisted at P50.

To determine the number of each glial cell type, we examined three pairs of nerves from 3-month-old transgenic mice and three pairs from their wild-type littermates by electron microscopy. We examined two transverse sections from the central third of the nerve, at least $100 \mu \mathrm{m}$ apart. We counted only those cells within the boundary of the glial limiting membrane, and we did not count endothelial cells. Mature oligodendrocytes and astrocytes were easy to identify (Peters et al.,

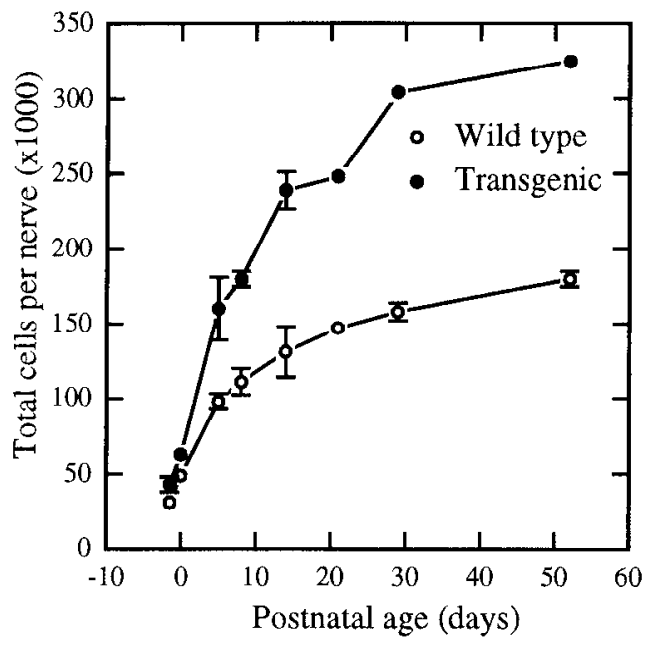

Figure 2. The increase in total cells in the optic nerves of wild-type and transgenic (line 73) littermates during development. Cell numbers were determined by measuring the total DNA in the nerve and dividing by the amount of DNA per cell. Results are expressed as mean \pm SEM of single nerves from 3-10 animals per group.
Table 2. Identity of glial cells in electron micrographs of adult optic nerves

\begin{tabular}{lcc} 
& Wild type & Transgenic \\
\hline Oligodendrocytes & $91 \pm 4$ & $204 \pm 4$ \\
Astrocytes & $50 \pm 4$ & $116 \pm 9$ \\
Oligodendrocyte precursors & $6 \pm 4$ & $11 \pm 1$ \\
Microglia & $3 \pm 2$ & $7 \pm 1$ \\
\hline
\end{tabular}

Cell counts were made on electron micrographs of transverse sections of optic nerves from 3-month-old adult transgenic (line 73) and wild-type mice. Two sections were taken, at least $100 \mu \mathrm{m}$ apart, from the central third of both nerves from three animals in cach group. The results are expressed as the mean \pm SEM of 12 sections per group.

1991): oligodendrocytes had a dark cytoplasm, dark nucleoplasm with clumped chromatin, many free and membranebound ribosomes, abundant microtubules, a well defined Golgi apparatus, and an endoplasmic reticulum often arranged in stacks; astrocytes, by contrast, had a lighter cytoplasm and nucleoplasm, frequently an irregularly shaped nucleus, and numerous intermediate filaments that were often in bundles. Microglial cells were more difficult to identify with certainty, but typical ones contained clumped chromatin, a long, winding endoplasmic reticulum, and often phagocytosed debris. A previous study defined the identifying characteristics of oligodendrocyte precursor cells (Fulton et al., 1992): they were small with little cytoplasm, no intermediate filaments, clumped chromatin at the periphery of the nucleus, and a density intermediate between oligodendrocytes and astrocytes. We were unable to classify $\sim 3 \%$ of the cells. As shown in Table 2 , there were approximately twice as many oligodendrocytes, astrocytes, microglial cells, and oligodendrocyte precursor cells in nerves from $b c l-2$ transgenic mice compared with nerves from their wild-type littcrmates. There were no obvious differences in glial cell size in the two types of nerves, consistent with the finding that both total cell number and nerve volume were approximately doubled.

\section{Cell death}

To compare the amount of glial cell death in transgenic and wild-type optic nerves, we stained serial longitudinal frozen sections of nerves from mice of different ages with PI to identify normal and pyknotic nuclei, and counted the total number of pyknotic nuclei in each nerve. The total numbers of dead cells were significantly lower in transgenic nerves than in wild-type nerves at P14 and P21, but were not significantly different at P8 or P29 (Fig. 3).

It has been shown that all cell death in the postnatal rat optic nerve is confined to the oligodendrocyte cell lineage (Barres et al., 1992). To help determine whether this is also the case in transgenic and wild-type mouse optic nerves, we double-labeled frozen sections of these nerves with PI to identify dead cells and antiGFAP antibodies to identify astrocytes. None of the dead cells was GFAP ${ }^{+}$, as shown previously in the rat optic nerve (Barres et al., 1992). It is possible, however, that astrocytes that undergo PCD lose their GFAP. To test this possibility, we treated optic nerve explants from $\mathrm{P} 7$ animals with a high concentration $(1 \mu \mathrm{M})$ of the protein kinase inhibitor staurosporine for $3 \mathrm{~d}$ to induce PCD. Frozen sections were then cut and stained with PI and anti-GFAP antibodies: many pyknotic cells were seen to be brightly $\mathrm{GFAP}^{+}$, indicating that astrocytes do not necessarily lose their GFAP when they undergo PCD. Thus, it is likely that most of the dead cells in the postnatal mouse optic nerve belong to the 


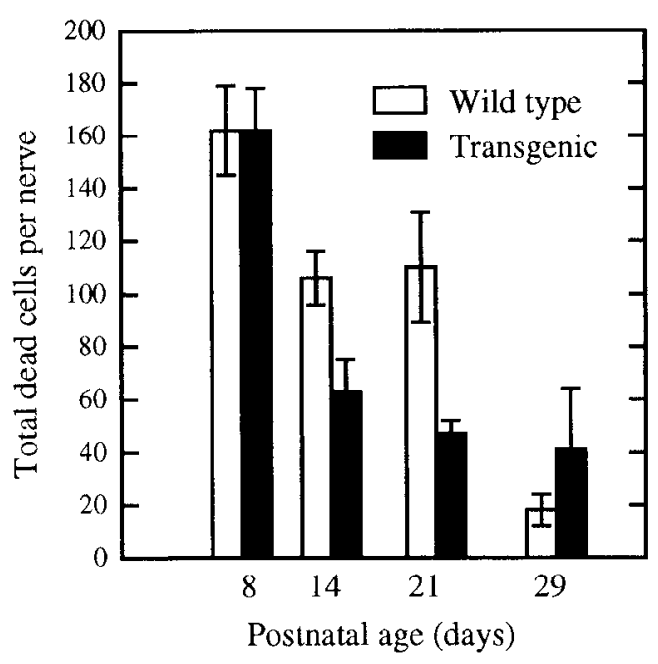

Figure 3. Cell death in the optic nerves of wild-type and transgenic (line 73) mice of various ages. All of the dead cells were counted in Pl-stained, serial frozen sections of single nerves from three animals at each age. The results are expressed as mean \pm SEM.

oligodendrocyte lincage, and at least some of the increase in oligodendrocyte number in the transgenic optic nerve reflects a decrease in cell death.

\section{Cell proliferation}

To compare the numbers of dividing cells in the optic nerves of transgenic and wild-type mice, we injected BrdU into the peritoneum of P8, P14, P21, and P29 mice. One hour later the mice were killed, serial frozen sections of their optic nerves were stained with anti-BrdU antibody, and all the $\mathrm{BrdU}^{+}$cells in each nerve were counted. As shown in Figure 4, the numbers of $\mathrm{BrdU}^{+}$cells were increased in transgenic compared with wild-type nerves at all four ages. Because most of the increase in astrocyte numbers in rodent optic nerve occurs in the first two postnatal weeks [and most of the increase in oligodendrocyte numbers occurs after this time (Skoff, 1990; Barres et al., 1992)], many of the BrdU-labeled cells at P8 in our experiments would be expected to be astrocytes, whereas most

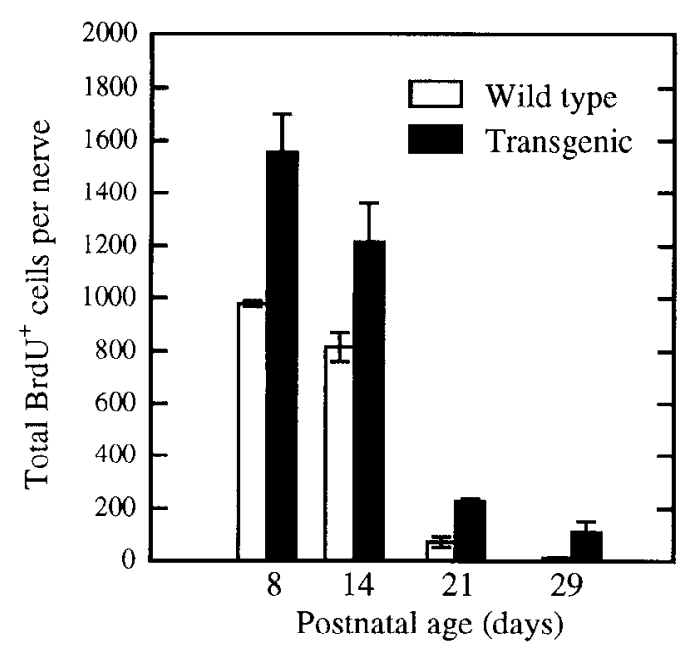

Figure 4. Cell proliferation in the optic nerves of wild-type and transgenic (line 73) optic nerves at various ages. Mice were injected twice with BrdU 2 hr apart. Two hours after the final injection, serial frozen sections of the optic nerve were cut and stained with anti-BrdU antibody. All of the $\mathrm{BrdU}^{+}$cells were counted in single nerves from three to four animals at each age. The results are expressed as mean \pm SEM.
Table 3. Astrocyte proliferation in overnight cultures of 95 optic nerve cells

\begin{tabular}{lcc} 
& Wild type & Transgenic \\
\hline$\% \mathrm{GFAP}^{+}$cells & $42 \pm 7$ & $64 \pm 8$ \\
$\% \mathrm{BrdU}^{+}$cells & $0.8 \pm 0.1$ & $1.1 \pm 0.1$ \\
$\% \mathrm{BrdU}^{+}$cells expressing GFAP & $15 \pm 2$ & $30 \pm 4$
\end{tabular}

P5 transgenic (line 73) mice received two intraperitoncal injections of BrdU $2 \mathrm{hr}$ apart and were killed 2 hr after the last injection. Cell suspensions were prepared from the optic nerves and cultured overnight. The cells were stained for GFAP and BrdU, and at least 1,000 cells were assessed. The results are expressed as means \pm SEM of threc separate experiments.

of the labeled cells at later ages would be expected to be oligodendrocyte precursor cells.

Because astrocytes were increased as much as oligodendrocytes in adult transgenic optic nerves (see Table 2), and astrocytes seem not to undergo normal cell death in the optic nerve, it was expected that the proliferation of astrocytes or their precursors would be greater in transgenic nerves than in wild-type nerves. To confirm this, we looked at BrdU incorporation into astrocytes in P5 nerves. We injected BrdU twice, 2 hr apart, and killed the mice $2 \mathrm{hr}$ after the last injection. In some mice we labeled serial frozen sections of optic nerve with anti-BrdU antibody and counted the total number of $\mathrm{BrdU}^{+}$cells in the nerves (Table 3). In others, we prepared cells from the optic nerve, cultured them overnight, and double-labeled them for BrdU and GFAP. Although the proportion of $\mathrm{BrdU}^{+}$cells in transgenic nerves was not very different from that in wild-type nerves (data not shown), $-30 \%$ of the $\mathrm{BrdU}^{+}$cells were $\mathrm{GFAP}^{+}$in the cultures of transgenic cells compared with $\sim 15 \%$ in cultures of wild-type cells (Table 3 ), suggesting that astrocyte proliferation was greater in the transgenic nerves. Moreover, the increased number of total cells in the transgenic nerves compared with wild-type nerves at P5 could be entirely accounted for by the increased number of $\mathrm{GFAP}^{+}$astrocytes: Figure 2 shows that there were $\sim 55,000$ more cells in the transgenic nerves at P5 and, if one uses the numbers for the proportions of $\mathrm{GFAP}^{+}$cells from Table 3 to calculate the total numbers of astrocytes in the nerves at P5, there were $\sim 55,000$ more astrocytes.

These findings suggest that the difference in astrocyte numbers between transgenic and wild-type optic nerves mainly reflects an increase in the proliferation of astrocytes and/or their precursors, whereas the difference in oligodendrocyte numbers reflects both a decrease in normal oligodendrocyte death and an increase in oligodendrocyte precursor proliferation.

\section{Bcl-2 transgene expression in optic nerve glial cells}

In the CNS, NSE is thought to be expressed only in neurons and neuroendocrine cells (Schmechel and Marangos, 1983). This is also reported to be the case for lac $Z$ transgenes controlled by an NSE promoter, in which transgene expression was detected by $\beta$-galactosidase staining (Forss-Petter et al., 1990). To test whether glial cells in the optic nerve of the $b c l-2$ transgenic mice express the transgene, we stained cells isolated from the optic nerve with an anti-human Bcl-2 monoclonal antibody, together with cell-type-specific antibodies to identify the glial cells. To our surprise, many optic nerve cells isolated from transgenic mice from line 73 expressed the human $\mathrm{Bcl}-2$ protein, including all of the $\mathrm{MBP}^{+}$oligodendrocytes and almost all of the $\mathrm{GFAP}^{+}$astrocytes (Table 4); none of the cells isolated from wild-type littermates did so. Microglial cells, identified by their Fc receptors 


\begin{tabular}{llll}
\hline \multicolumn{4}{l}{ Table 4. Expression of human Bcl-2 protein in optic nerve glial cells } \\
$\begin{array}{llll}\text { Transgenic } \\
\text { mice line }\end{array}$ & Age & $\begin{array}{l}\text { \% Human Bcl-2 } \\
\text { oligodendrocytes }\end{array}$ & $\begin{array}{l}\text { \% Human Bcl-2 } \\
\text { astrocytes }\end{array}$ \\
\hline Line 73 & P7 & 100 & $97 \pm 4$ \\
Line 73 & P14 & 100 & $99 \pm 2$ \\
\hline Line 71 & P7 & $28 \pm 4$ & $17 \pm 3$ \\
Line 71 & P14 & $30 \pm 2$ & $10 \pm 1$
\end{tabular}

Cells dissociated from optic nerve were allowed to adhere to a coverslip for $20 \mathrm{~min}$ and then were double-stained for human $\mathrm{Bcl}-2$ and for cell type, as described in Materials and Methods. At least 160 cells were assessed on each coverslip. The results are cxpressed as means \pm SEM of three separate experiments.

(Raff et al., 1979), and $\mathrm{GFAP}^{-}$flat cells (presumptive meningeal cells) in cultures prepared from transgenic nerves, did not express detectable human Bcl-2, although some microglial cells were weakly stained (data not shown). When frozen sections of adult optic nerves were stained with anti-human Bcl-2 antibody, most of the glial cells in transgenic nerves were weakly labeled, as apparently were the axons, whereas there was no staining of wikd-type nerves (data not shown).

\section{Effect of transgene expression on oligodendrocyte survival in culture}

To determine whether the expression of the $b c l-2$ transgene could protect optic nerve oligodendrocytes from PCD when cultured without added survival signals, we dissociated cells from P8 optic nerve and cultured them at low density in DMEM. Cells derived from wild-type and transgenic animals were cultured together so that their survival could be directly compared in the samc cnvironment. After 1 and $3 \mathrm{~d}$, cultures were stained for $\mathrm{GC}$ and human $\mathrm{Bcl}-2$. After $1 \mathrm{~d}$, there were many viable $\mathrm{GC}^{+}$oligodendrocytes, and $78 \pm 1 \%$ of them were $\mathrm{Bcl}-2^{+}$(mean $\pm \mathrm{SEM}$ of 3 cultures), consistent with the fact that 4 of 6 of the mice used to prepare the optic nerve cells expressed the $b c l-2$ transgene. After $3 \mathrm{~d}$, the great majority of $\mathrm{GC}^{+}$cells were apoptotic, but of those that were alive, $82 \pm 3 \%$ were $\mathrm{Bcl}-2^{+}$(mean \pm SEM of 3 cultures). Thus, the expression of the transgene failed to protect oligodendrocytes from PCD in culture in the absence of added survival factors.

\section{Effect of optic nerve transection}

Normally, when the developing optic nerve is cut behind the eye, RGCs undergo PCD (Snider et al., 1993), their disconnected axons rapidly degenerate, and oligodendrocytes in the nerve die (David et al., 1981) by PCD (Barres et al., 1993). To determine whether the expression of the $b c l-2$ transgene in RGCs and oligodendrocytes protects the cells and axons from these fates after transection, we cut the optic nerve of P18 transgenic and wild-type mice and examined the nerves after $4 \mathrm{~d}$. We stained frozen sections with the RT97 monoclonal anti-neurofilament antibody (Wood and Anderton, 1981) to visualize the axons, and with PI to identify pyknotic glial cell nuclei. Very few axons were seen in either the wild-type or transgenic-cut nerves, either by RT97 staining or by phase-contrast microscopy (Fig. 5). Thus, bcl-2 expression in RGCs does not protect their axons from Wallerian degeneration. Moreover, the number of dead glial cells was at least threefold greater in the cut transgenic nerve than in the cut wild-type nerve (Fig. 6). None of the dead cells was GFAP $^{+}$(not shown), consistent with the possibility that they were oligodendrocytes, as shown previously in transected rat optic nerves. Thus, $b c l-2$ expression in oligodendrocytes does not appear to protect them from PCD after optic nerve transection.

To confirm the presence of human $\mathrm{Bcl}-2$ in transgenic $\mathrm{RGC}$ axons (suggested by the weak staining of axons in frozen sections of adult optic nerves mentioned above), we cultured explants of retina from neonatal transgenic mice and stained the cultures with anti-human Bcl-2 antibody. As shown in Figure 7, RGC axons were strongly $\mathrm{Bcl}-2^{+}$.

To determine whether the expression of the $b c l-2$ transgene would protect the soma of RGCs from axotomy-induced PCD, we cultured explants of adult retina from transgenic and wild-type mice and, after $4 \mathrm{~d}$ in culture, stained them with an antiserum that labels RGCs. We counted the numbers of RGC somata remaining in the ganglion cell layer of measured lengths of retinal sections and compared them with those in uncultured adult retina. Whereas only $30 \%$ of the RGC somata survived in explants of wild-type retina, $90 \%$ survived in explants of transgenic retina, indicating that the $b c l-2$ transgene protects the RGC soma from axotomy-induced PCD, even though it fails to protect the isolated transected axon.

\section{A different $\mathbf{B C l}-2$ transgenic mouse line}

To help determine whether the increase in astrocytes and oligodendrocytes seen in the $b c /-2$ transgenic mouse line 73 was directly related to the expression of the transgene in the glial cells themselves (rather than indirectly related to the increased number of axons), we studied a second transgenic mouse line expressing the same transgene from the same promoter. In this mouse line, however, the transgene is not expressed in RGCs, and the optic nerves are normal in size (Martinou et al., 1994). As shown in Figure 8 , the number of glial cells in the optic nerves of these mice was not significantly different from their wild-type littermates at various ages. We also found that there was no significant difference in the total number of dead cells seen at P14, an age when we found a greatly reduced number of dead cells in optic nerves from line 73 animals compared with wild-type litternates: the total number of PI-stained pyknotic nuclei in P14 transgenic line 71 nerves was $97 \pm 13$, compared with $90+9$ in wild-type nerves, (mean \pm SEM of 3 nerves in both cases). Nonetheless, many of the glial cells, including both astrocytes and oligodendrocytes, expressed the human Bcl-2 protein (Table 4). Although the proportion of glial cells that expressed the transgene was less than in line 71, the amount of $\mathrm{Bcl}-2$ protein expressed in the positive cells was at least as great, if not greater, when quantificd in a confocal fluorescence microscope: in human Bcl-2 ${ }^{1}$ glial cells from the 73 line, the mean number of arbitrary units was $41 \pm 4$, whercas in human $\mathrm{Bcl}-2^{+}$glial cells from the 71 line, the mean number of arbitrary units was $50.3 \pm 10(n=25$ cells in both cases $)$. In both lines, there were no significant differences in the proportions of oligodendrocytes that expressed human $\mathrm{Bcl}-2$ at $\mathrm{P} 7$ and $\mathrm{P} 14$ (Table 4).

\section{DISCUSSION}

\section{Axons}

We find that optic nerves from the $b c l-2$ transgenic mouse line 73 (Martinou et al., 1994) contain $80 \%$ more axons than wild-type nerves. This is the result of a decrease in the normal postnatal loss of RGC axons: in wild-type optic nerves, $60 \%$ of the axons are lost between birth and P14, whereas only $35 \%$ are lost in the transgenic nerves

Interestingly, the expression of the $b c l-2$ transgene in $\mathrm{RGCs}$ protects the cell body from PCD when the axon is cut, but it 


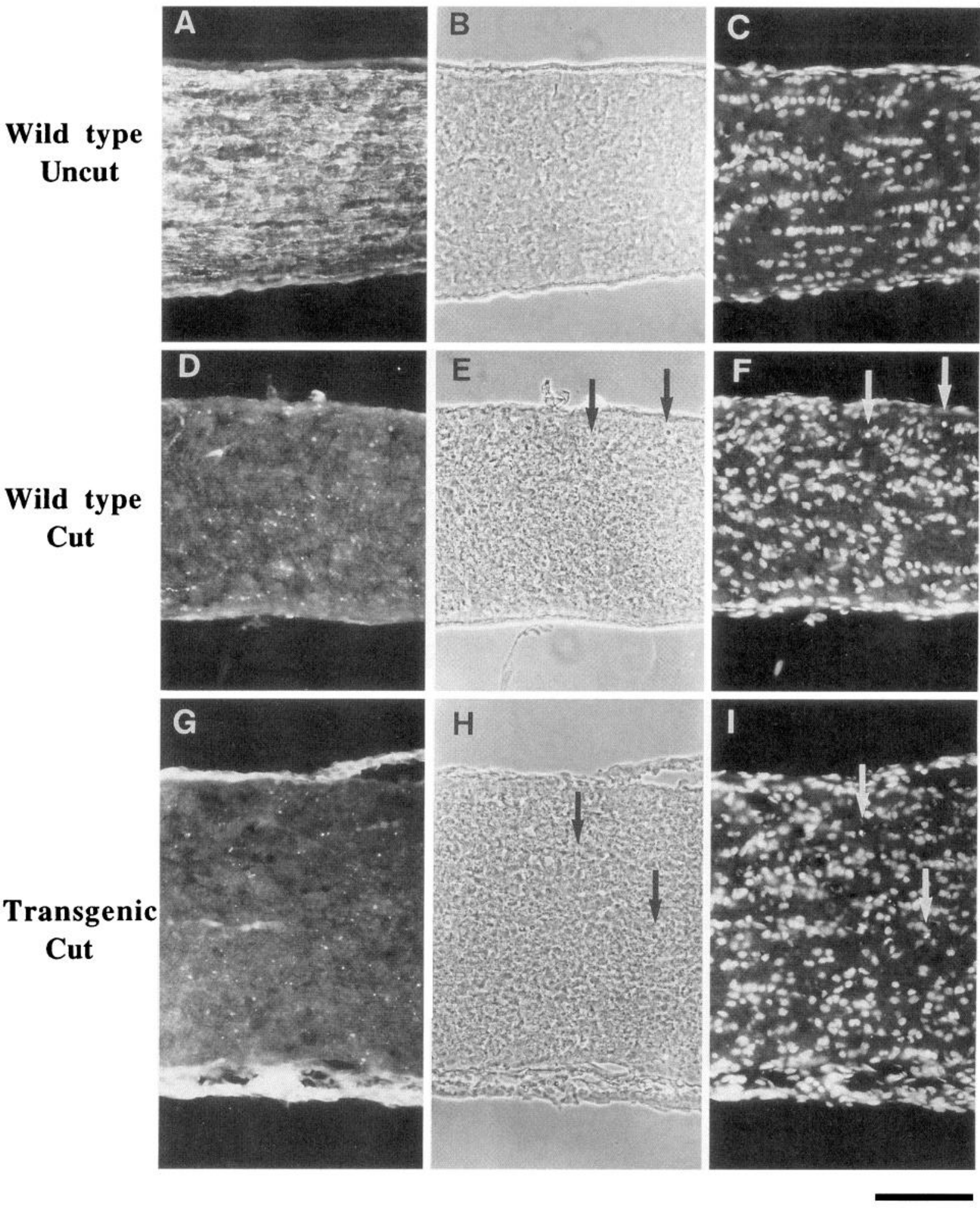

Figure 5. Immunofluorescence and corresponding phase-contrast micrographs of frozen sections of normal $(A-C)$ or cut $(D-I)$ P18 optic nerves from wild-type $(A-F)$ or transgenic $(G-I)$ mice. The cut optic nerves were studied $4 \mathrm{~d}$ after transection. The sections were stained with either anti-neurofilament antibody $(A, D, G)$ or PI $(C, F, I)$. Arrows point to examples of dead cells. Scale bar, $100 \mu \mathrm{m}$.

does not protect the isolated axon from Wallerian degeneration, even though the transgene-encoded $\mathrm{Bcl}-2$ protein is present in both the axon and the cell body. These results are consistent with other findings that suggest that the mechanisms of PCD and Wallerian degeneration are different. Buckmaster et al. (1995) showed that when sympathetic neurons from C57BL/6 Wld mutant mice, the axons of which undergo Wallerian degeneration more slowly than those from wild-type mice (Perry et al., 1990), are cultured without nerve growth factor (NGF), their cell bodies undergo PCD, whereas their 


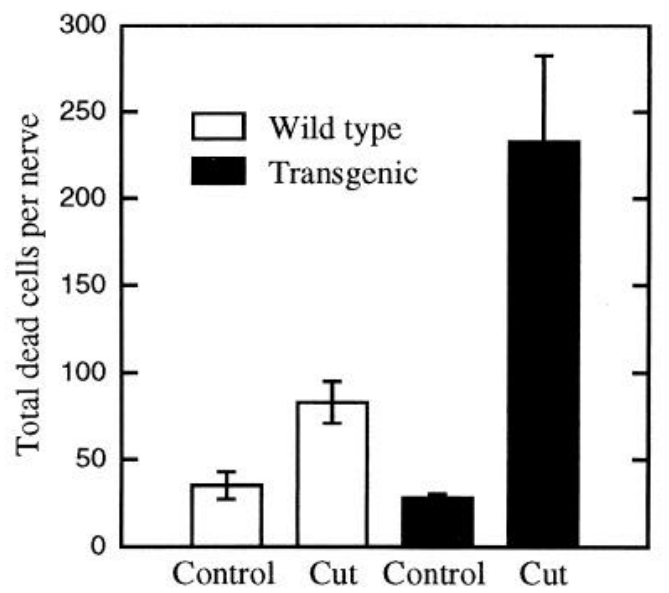

Figure 6. The effect of nerve transection on the numbers of dead cells in wild-type and transgenic (line 73) nerves $4 \mathrm{~d}$ after transection. The experiments were performed and analyzed as in Figure 3. Cells in three nerves from each group were counted and expressed as mean \pm SEM.

neurites remain intact. Moreover, when sympathetic (Garcia et al., 1992) and sensory (Gagliaridini et al., 1994) neurons protected by $b c l-2$ or the anti-apoptotic viral gene $\mathrm{crm} A$, respectively, are deprived of NGF, the cell bodies survive but the neurites usually do not. In addition, $b c l-2$ overexpression in a mutant mouse with a progressive motor neuronopathy (the pmn mouse) prevents the loss of motor neuron cell bodies, but
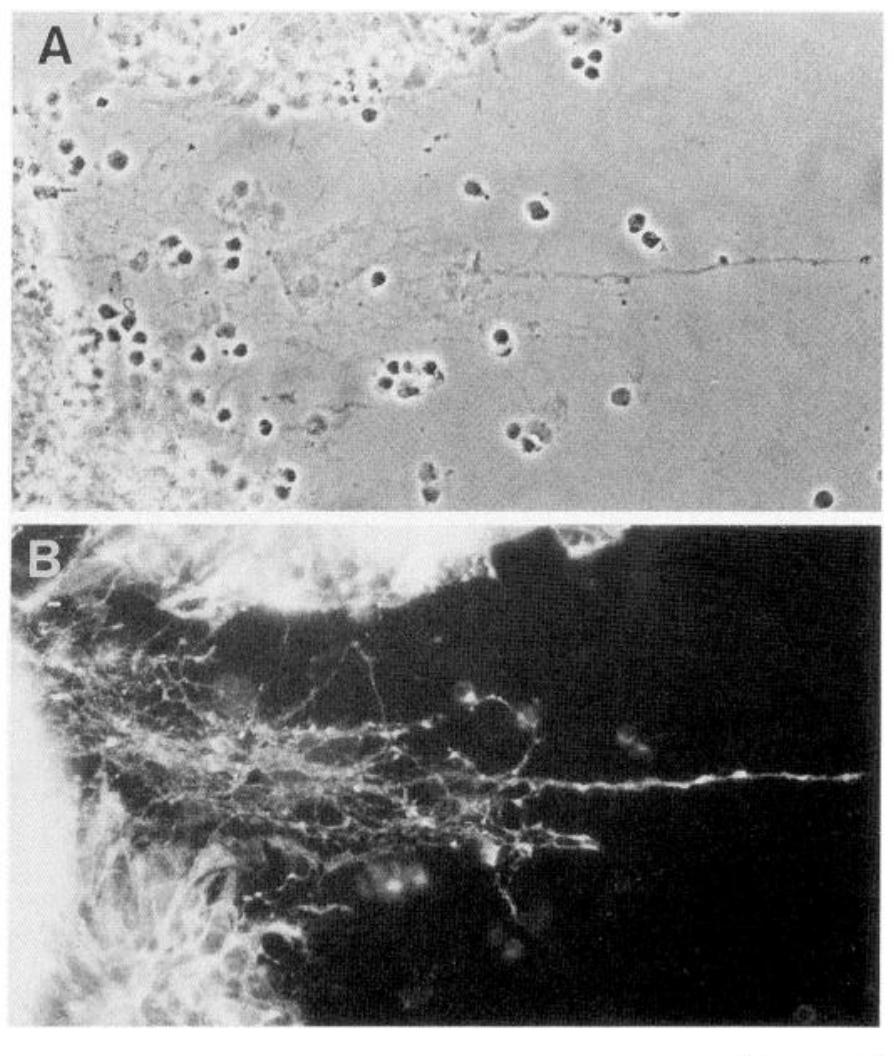

Figure 7. Immunofluorescence $(A)$ and corresponding phase-contrast $(B)$ micrograph of a retinal explant from a P1 transgenic (line 73) mouse after $2 \mathrm{~d}$ in culture. The culture was stained with an anti-human Bcl-2 antibody. Note that $\mathrm{Bcl}-2$ protein is present in the axons. Scale bar, $50 \mu \mathrm{m}$.

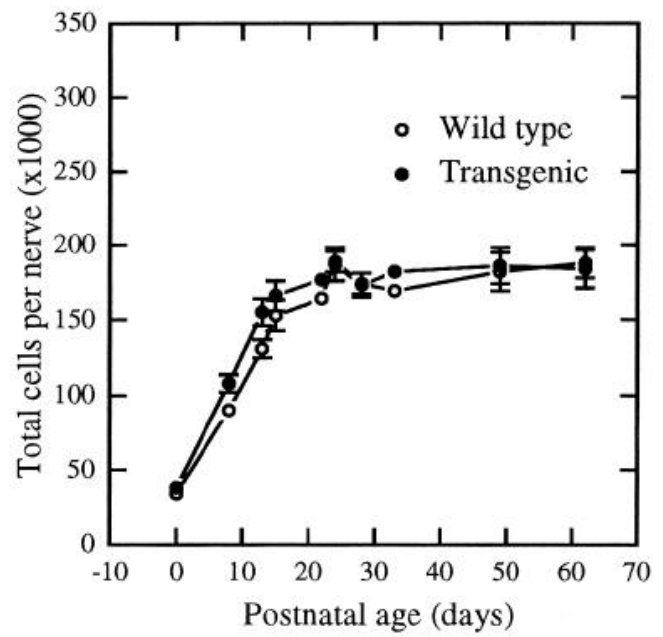

Figure 8. The increase in total cells in the optic nerves of wild-type and transgenic (line 71) littermates during development. The experiments were performed and analyzed as in Figure 2. Results are expressed as mean $\pm \mathrm{SEM}$ of single nerves from three to eight animals per group.

not of motor neuron axons, and the progressive weakness and death of the mouse is unaffected (Sagot et al., 1995).

\section{Oligodendrocytes}

We showed previously in the developing rat optic nerve that axons are required for oligodendrocyte survival (Barres et al., 1993) and that $50 \%$ of the oligodendrocytes produced in the rat optic nerve usually die within 2-3 d after they develop (Barres et al., 1992). We suggested that this massive death reflects a competition for axon-dependent survival signals (Barres et al., 1992). Forcing newly formed oligodendrocytes to compete for limiting amounts of axon-dependent signals may help match the final number of oligodendrocytes to the number of axons requiring myelination (Barres et al., 1993). A prediction of this hypothesis is that an increase in axon numbers should decrease oligodendrocyte death.

Our findings are consistent with this prediction. The number of oligodendrocytes in the transgenic optic nerve is twice that in the wild-type optic nerve, and at least some of the increase results from a decrease in normal oligodendrocyte death. During the second and third postnatal weeks, when oligodendrocyte death would be expected to be maximal (Barres et al., 1992), the number of dead cells in transgenic optic nerves is significantly less than in nontransgenic nerves. We showed previously that $90 \%$ of the dead cells in the postnatal rat optic nerve are oligodendrocytes and $10 \%$ are oligodendrocyte precursor cells (Barres et al., 1993). Although we have not directly identified the dead cells in the mouse optic nerve, it seems likely that most of them belong to the oligodendrocyte lineage, because none of them express the astrocyte marker GFAP.

Three lines of evidence suggest that the decrease in normal oligodendrocyte death that occurs in the transgenic optic nerve is mainly secondary to the increase in axons, astrocytes, or both, rather than directly related to the expression of the $b c l-2$ transgene in oligodendrocytes. First, transection of the transgenic nerve at P18 leads to increased glial cell death, which is proportionally even greater than that seen after transection of wild-type nerves. Because none of the dead cells in the cut nerve is $\mathrm{GFAP}^{+}$and, in the rat, the increased cell death in transected optic nerves is confined to oligodendrocytes (Barres et al., 1993), it seems likely that the increased cell death in the cut mouse optic nerve is also mainly oligodendrocyte death. Thus, the expression of the $b c l-2$ transgene in oligodendrocytes does 
not seem to protect them from PCD when they are deprived of axonal signals in vivo. Second, when deprived of survival signals in vitro, transgenic oligodendrocytes do not survive better than wildtype oligodendrocytes. Third, a different $b c l-2$ transgenic mouse line (line 71), in which the transgene is not expressed in RGCs (Martinou et al., 1994) but is expressed in $30 \%$ of the oligodendrocytes and $15 \%$ of the astrocytes in the optic nerve, has a normal number of optic nerve glial cells (assessed at various ages) and a normal number of dead cells (assessed at P14). Moreover, the proportion of oligodendrocytes expressing the transgene in this line does not increase from P8 to P14, suggesting that expression of the transgene does not confer a selective survival advantage on these oligodendrocytes. Because the amount of human $\mathrm{Bcl}-2$ protein expressed in individual glial cells is at least as great in line 71 as in line 73 , it seems unlikely that the expression of the $b c l-2$ transgene in oligodendrocytes in line 73 protects these cells from normal cell death.

Axons normally promote the proliferation of oligodendrocyte precursor cells in the developing optic nerve (Barres and Raff, 1993). Two lines of evidence suggest that an increase in oligodendrocyte precursor cell proliferation also contributes to the increase in oligodendrocyte numbers in the optic nerves of transgenic line 73. First, the number of oligodendrocyte precursor-like cells in the adult optic nerves of these transgenic mice is approximately twice that in wild-type mice. Second, the total number of cells labeled by an injection of BrdU is higher in the transgenic compared with wild-type optic nerves at P14, P21, and P29, when most of the dividing cells in the nerve would be expected to be oligodendrocyte precursor cells (Barres et al., 1992). It is unclear whether the increase in oligodendrocyte precursor proliferation is directly related to the increase in axons, astrocytes, or both.

\section{Astrocytes}

Astrocytes are increased as much as oligodendrocytes in the transgenic optic nerve. Because astrocytes apparently do not die in the postnatal rodent optic nerve either during development (Barres et al., 1992) or after nerve transection (Barres et al., 1993), it seems likely that the increase reflects increased proliferation of astrocytes and/or their precursors in the transgenic nerve. Although the proportions of cells synthesizing DNA in the transgenic and wild-type optic nerves at $P 5$ are not very different, twice as many of these cells are $\mathrm{GFAP}^{+}$astrocytes in overnight cultures of transgenic compared with wild-type nerves, suggesting that proliferation of astrocyte lineage cells is greater in the transgenic nerve at P5. Moreover, there are $\sim 55,000$ more glial cells in transgenic optic nerves than in wild-type nerves at P5; all of this increase can be accounted for by the increase in astrocyte numbers. Although the $b c l-2$ transgene is expressed in almost all of the astrocytes in transgenic optic nerves, it is unlikely that the transgene is directly responsible for their increased proliferation, because overexpression of $b c l-2$ has not been reported to increase cell proliferation. It seems more likely that the increase in axons in the transgenic optic nerve is either directly or indirectly responsible for the increased proliferation, a conclusion supported by our own previous finding that there are half as many astrocytes in rat optic nerves that were cut at birth and studied $15 \mathrm{~d}$ later, compared with uncut nerves (David et al., 1984).

\section{Microglia}

Microglia also seem to be increased approximately twofold in the transgenic compared with wild-type optic nerves. The mechanism(s) underlying this apparent increase are unknown because little is known about how the number of microglial cells in the nerve is normally controlled. These cells migrate into the developing nerve via the blood vessels and pia-arachnoid, which are presumably increased in the transgenic nerves; this increase by itself might be enough to account for the increase in microglial cells. Because cultured astrocytes produce factors that are mitogenic for cultured microglial cells (Shafit-Zagardo et al., 1993; Lee et al., 1994), it is also possible that the increase in microglia is secondary to the increase in astrocytes.

\section{Control of cell numbers}

It remains a challenge to understand how the number of cells in an organ or organism is determined. Our findings in the $b c l-2$ transgenic optic nerve provide a glimpse at how complex the mechanisms arc likely to be. The finding that the ratios of the axons to the three major glial cell types are maintained in the enlarged transgenic nerve is remarkable. It indicates that the different cell types can interact with one another and with axons to control their proliferation and survival in a coordinated manner to adjust their numbers rather than their size when the number of axons is increased. A similar adjustment occurs when the number of axons is decreased: in an extreme case in which axons fail to enter the optic stalks in the ocular retardation mouse, glial cells do not develop there and the mice end up without optic nerves (Silver and Robb, 1979).

\section{REFERENCES}

Ausubel I, Brent R, Kingston RE, Moore DD, Seidman JG, Smith JA, Struhl K (1991) Current protocols in molecular biology. New York: Wiley.

Barres BA, Raff MC (1993) Proliferation of oligodendrocyte precursor cells depends on electrical activity in axons. Nature 361:258-260.

Barres BA, Hart IK, Coles HSR, Burne JF, Voyvodic JT, Richardson WD, Raff MC (1992) Cell death and control of cell survival in the oligodendrocyte lineage. Cell 70:31-46.

Barres BA, Jacobson MD, Schmid R, Sendtner M, Raff MC (1993) Does oligodendroctye survival depend on axons? Curr Biol 3:489-497.

Bonfanti L, Candeo P, Piccinini M, Carmignoto G, Comelli MC, Ghidella S, Bruno R, Gobetto A, Merighi A (1992) Distribution of protein gene product 9.5 (PGP 9.5) in the vertebrate retina: evidence that immunoreactivity is restricted to mammalian horizontal and ganglion cells. $J$ Comp Neurol 322:35-44.

Bottenstein JE, Sato GH (1979) Growth of a rat neuroblastoma cell line in serum-free supplemented medium. Proc Natl Acad Sci USA 76:514--517

Buckmaster EA, Perry VH, Brown MC (1995) The rate of Wallerian degeneration in cultured neurons from wild type and C57BI/WId mice depends on time in culture and may be extended in the presence of elevated $\mathrm{K}^{+}$levels. Eur J Neurosci 7:1596-1602.

Cowan WM, Fawcett JW, O'Leary DDM, Stanfield BB (1984) Regressive events in neurogenesis. Science 225:1258-1265.

David S, Miller RH, Patel R, Raff MC (1984) Effects of neonatal transection on glial cell development in the rat optic nerve: evidence that the oligodendrocyte-type 2 astrocyte lineage depends on axons for its survival. J Neurocytol 13:961-974.

Dubois-Dauphin M, Frankowski H, Tsujimoto Y, Huarte J, Martinou J-C (1994) Neonatal motorneurons overexpressing the bcl-2 protooncogene in transgenic mice are protected from axotomy-induced cell death. Proc Natl Acad Sci USA 91:3309-3313.

Forss-Petter S, Danielson PE, Catsicas S, Battenberg E, Price J, Nerenberg M, Sutcliffe JG (1990) Transgenic mice expressing $\beta$-galactosidase in mature neurons under neuron-specific enolase promoter control. Neuron 5:187-197.

Fulton BP, Burne JF, Raff MC (1992) Visualization of O-2A progenitor cells in developing and adult rat optic nerve by quisqualate-stimulated cobalt uptake. J Neurosci 12:4816-4833.

Gagliaridini V, Fernandez P, Lee R, Drexler H, Rotello R, Fishman M, Yuan J (1994) Prevention of vertebrate neuronal death by the crmA gene. Science 263:754-756.

Garcia I, Martinou I, Tsujimoto Y, Martinou J-C (1992) Prevention of programmed cell death of sympathetic neurons by the bcl-2 protooncogene. Science 258:302-304.

Gard AL, Pfeiffer SE (1989) Oligodendrocyte progenitors isolated directly from developing telencephalon at a specific phenotypic 
stage: myelinogenic potential in a defined environment. Development 106:119-132.

Hardy R, Reynolds R (1991) Proliferation and differentiation potential of rat forebrain oligodendrocyte progenitors both in vitro and in vivo. Development 111:1061-1080.

Labarca C, Paigen K (1980) A simple, and sensitive DNA assay procedure. Anal Biochem 102:344-352.

Lee S, Liu W, Brosnan C, Dickson D (1994) GM-CSF promotes proliferation of human fetal and adult microglia in primary culture. Glia 12:309-318

Magaud JP, Sargent I, Clarke PJ, Ffrench M, Rimokh R, Mason DY (1989) Double immunocytochemistry labelling of cell and tissue samples with monoclonal anti-bromodeoxyuridine. J Histochem Cytochem 37:1517-1527.

Martinou J-C, Dubois-Dauphin M, Staple JK, Rodriguez I, Frankowski H, Missotten M, Albertini P, Talabot D, Catsicas S, Pietra C, Huarte J (1994) Overexpression of $\mathrm{Bcl}-2$ in transgenic mice protects neurons from naturally occurring cell death and experimental ischemia. Neuron 13:1017-1030.

Oppenheim RW (1991) Cell death during development of the nervous system. Annu Rev Neurosci 14:453-501.

Perry VH, Brown MC, Lunn ER (1990) Very slow retrograde and Wallerian degeneration in the CNS of C57BL/Ola mice. Eur $\mathrm{J}$ Neurosci 3:102-105.

Peters A, Palay SL, Webster HF (1991) The fine structure of the nervous system, pp 273-311. Oxford: Oxford UP.

Pezzella F, Tse AGD, Cordell JL, Pulford KAF, Gatter KC, Mason DY (1990) Expression of the bcl-2 oncogene is not specific for the 14;18 chromosomal translocation. Am J Pathol 137:225-232.

Pruss $R$ (1979) Thy-1 antigen on astrocytes in long-term cultures of rat central nervous system. Nature 303:390-396.

Purves D, Voyvodic JT (1987) Imaging mammalian nerve cells and their connections over time in living animals. Trends Neurosci 10:398-404.

Raff MC, Fields KL, Hakomori S-I, Mirsky R, Pruss RM, Winter I (1979) Cell-type-specific markers for distinguishing and studying neurons and the major classes of glial cells in culture. Brain Res 174:283-308.

Raff MC, Barres BA, Burne JF, Coles HSR, Ishizaki Y, Jacobson MD (1993) Programmed cell death and the control of cell survival: lessons from the nervous system. Science 262:695-700.
Ranscht B, Clapshaw P, Price J, Noble M, Seifert W (1982) Development of oligodendrocytes and Schwann cells studied with a monoclonal antibody against galactocerebroside. Proc Natl Acad Sci USA 79:2709-2713.

Reed JC (1994) Cellular mechanisms of disease series. Bcl-2 and the regulation of programmed cell death. J Cell Biol 124:1-6.

Rodriguez-Tarduchy G, Collins M, Lopez Rivas $\Lambda$ (1990) Regulation of apoptosis in IL-3 dependent hemopoietic cells by IL-3 and calcium ionophores. EMBO J 9:2997-3002.

Sagot Y, Dubois-Dauphin M, Tan SA, de Bilboa F, Aebischer $\mathbf{P}$, Martinou JC, Kato AC (1995) Bcl-2 over-expression prevents motoneuron cell body loss but not axonal degeneration in a mouse modle of a neurodegenerative disease. J Neurosci 15:7727-7733.

Schmechel D, Marangos P (1983) Neuron specific enolase as a marker for differentiation in neurons and neuroendocrine cells. In: Current methods in cellular neurobiology (Barker J, McKelvey J, eds), pp 1-62. New York: Wiley.

Shafit-Zagardo B, Sharma N, Berman J, Bornstein M, Brosnan C (1993) CSF-1 expression is upregulated in astrocyte cultures by $1 \mathrm{~L}-1$ and TNF and affects microglial proliferation and morphology in organotypic cultures. Int J Dev Neurosci 11:189-198.

Silver J, Robb R (1979) Studies on the development of the eye cup and optic nerve in normal mice and in mutants with congenital optic nerve aplasia. Dev Biol 68:175-190.

Skoff RP (1990) Gliogenesis in rat optic nerve: astroctyes are generated in a single wave before oligodendrocytes. Dev Biol 139:149 168.

Small RK, Riddle $P$, Noble M (1987) Evidence for migration of oligodendrocyte-type-2 astrocytc progenitor cells into the developing rat optic merve. Nalure 328:155-157.

Snider W, Elliott J, Yan Q (1993) Axotomy-induced neuronal death during development. J Neurobiol 23:1232-1246.

Temple S, Raff MC (1986) Clonal analysis of oligodendrocyte development in culture. Evidence for a developmental clock that counts cell divisions. Cell 44:773-779.

Williams MA, Pinon LGP, Linden R, Pinto LH (1990) The pearl mutation accelerates the schedule of natural cell death in the early postnatal retina. Exp Brain Res 82:393-400.

Wood JN, Anderton BH (1981) Monoclonal antibodies to mammalian neurofilaments. Biosci Rep 1:263-268. 